I. C. C. van der Horst

A. A. Voors

D. J. van Veldhuisen

\section{Treatment of heart failure with ACE inhibitors and beta-blockers}

\author{
What is next? Aldosterone receptor antagonists?
}

Angiotensin converting enzyme (ACE) inhibitors and beta-blockers have together become the backbone of the treatment of chronic heart failure (CHF) as both classes of drugs have been shown to reduce morbidity and mortality [1]. In addition, patients with CHF generally receive a number of other drugs, which include diuretics, digoxin, vasodilators (like nitrates, and calcium channel blockers), anti-arrhythmic drugs, anticoagulants, and more recently statins. Although these latter classes of drugs may be indicated for special indications (such as atrial fibrillation) none of them has been overall shown to improve outcome. This is in contrast with two other classes of drugs which were found to further reduce morbidity and mortality in patients with CHF when added to maximal medication, i.e. angiotensin II receptor blockers (ARBs) and aldosterone receptor antagonists (ARAs) [2-5].

In recent years, ARAs have also been increasingly studied in patients with established CHF and in those with LV dysfunction/CHF after MI, although

Received: 14 July 2006

Accepted: 21 December 2006

Published online: 15 February 2007

Dirk J. van Veldhuisen, MD, PhD (

Iwan C.C. van der Horst - Adriaan A. Voors

Thoraxcenter, Department of Cardiology

University Medical Center Groningen

PO Box 30001

9700 RB Groningen, The Netherlands

Tel.: +31-50/3612355

Fax: $+31-50 / 3614391$

E-Mail: d.j.van.veldhuisen@thorax.umcg.nl maybe not quite as much as ARBs. Aldosterone levels are increased in patients with CHF [6], and it is generally assumed that ACE inhibitors lead to a reduction in plasma aldosterone levels [7], probably by lowering the production of aldosterone from the adrenal gland by preventing angiotensin II and stimulation of the AT1 receptor. However, it has been observed that in a significant proportion of patients treated with ACE inhibitors the aldosterone levels increase again after several months [8]. Therefore, a role for ARAs in the treatment of CHF on top of ACE inhibition or ARBs seems reasonable. It has been discovered that next to the modulation of gene expression and translation of proteins that regulate electrolyte and fluid balance and subsequent bloodpressure homeostasis by aldosterone, it has rapid socalled non-genomic effects $[9,10]$. These non-genomic effects include activation of pathways involved in inflammation, oxidative signalling, and collagen formation. Treatment with ARAs leads to suppression of these pathways and results in a reduction of collagen formation and myocardial fibrosis, and improvement of endothelial function [11]. Under certain circumstances, aldosterone also may have several effects that could contribute to sudden cardiac death. This includes stimulation of central sympathetic drive, release of norepinephrine from peripheral sympathetic nerves, a decrease in heart rate variability and baroreceptor function, and a recently observed blockade of a mechanism that increases sodium channel density or increases calcium channel density and then decreases the transient outward current that would ameliorate QT prolongation, a risk factor for sudden death [12].

The two ARAs which have been studied in clinical trials are spironolactone and eplerenone. Spironolactone is a nonselective antagonist of the aldosterone receptor, binding also to other steroid receptors and causing a significant percentage of patients 


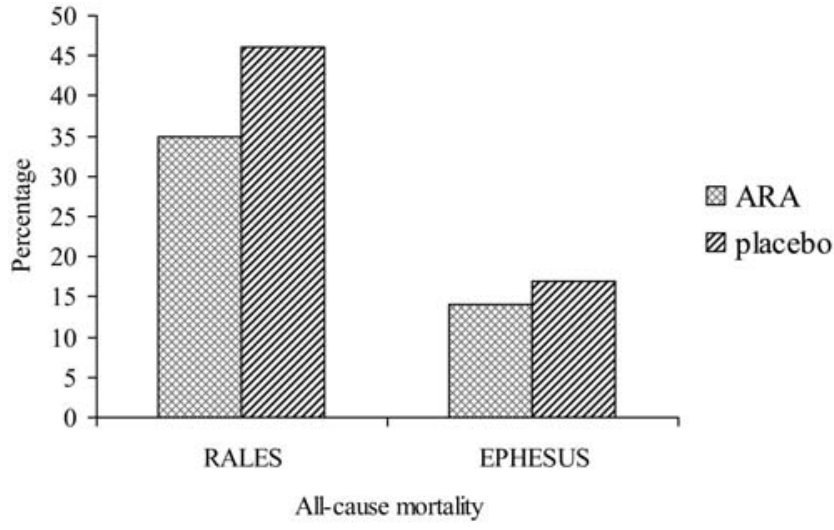

Fig. 1 All-cause mortality in RALES and EPHESUS (adapted from [4] and [5]). Mean follow-up period is 24 months in RALES and 16 months in EPHESUS

to have adverse effects such as gynaecomastia. Eplerenone is the first of a new class of drugs known as selective aldosterone receptor antagonists, which has a minimal effect at other steroid receptors.

Spironolactone was initially developed for the treatment for hypertension. Later its role in the treatment of CHF patients was studied. In the Randomized Aldactone Evaluation Study (RALES) trial, in 1663 patients with severe CHF (NYHA class III or IV) and a left ventricular ejection fraction of $\leq 35 \%$, administration of spironolactone $(25 \mathrm{mg})$ as add-on therapy to ACE inhibitors plus standard treatment (loop diuretics, digoxin and not frequently betablockers) had no significant effect on blood pressure or heart rate ('genomic effect') [4]. Despite this it resulted in $26 \%$ mortality reduction in cardiovascular mortality after a 24 month follow-up period (numbers needed to treat 11) (Fig. 1). However, spironolactone was associated with a higher incidence of gynaecomastia or breast pain (10 vs $1 \%)$, whereas the incidence of severe hyperkalemia was similar (2 vs $1 \%$ ). The role of spironolactone in patients with less advanced CHF has not been subject of randomized or large clinical trials. Furthermore, only $10 \%$ of the patients were taking beta-blockers and most patients received $<50 \%$ of their recommended doses of ACE inhibitors.

Eplerenone was developed more recently. Based on its selectivity it has a more favourable side effect profile. In the Eplerenone Post-Acute Myocardial Infarction Heart Failure Efficacy and Survival Study (EPHESUS), in 6632 patients with left ventricular ejection fraction of $\leq 40 \%$ and chronic heart failure following an acute myocardial infarction, treatment with the more selective eplerenone $(25 \mathrm{mg})$, resulted in a $17 \%$ reduction in cardiovascular mortality over a 16 month follow-up period (numbers needed to treat 44) (Fig. 1) [5]. This risk reduction was observed on top of treat-

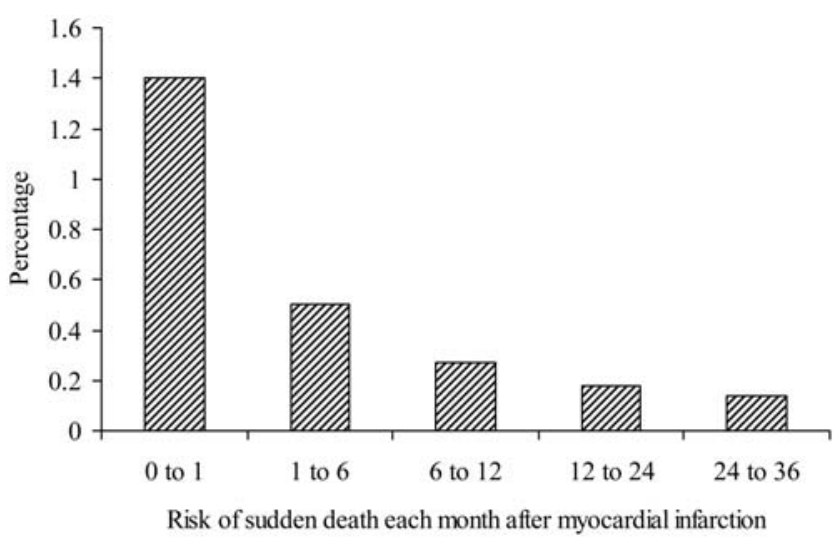

Fig. 2 The risk of sudden cardiac death after myocardial infarction (adapted from [12])

ment with ACE inhibitors or ARBs (87\%), diuretics (61\%) and beta-blockers (75\%). Treatment with eplerenone was associated with a higher incidence of hyperkalemia (5.5 vs $3.9 \%$ ) but lower incidence of hypokalemia ( 8.4 vs $13.1 \%$ ) while gynaecomastia was not increased ( 0.5 vs $0.6 \%)$.

ARAs may not only have structural effects on left ventricular function, but they may also reduce sudden death. This was first suggested in RALES [4]. In the EPHESUS it was shown that eplerenone caused a reduction of $37 \%$ in the incidence of sudden cardiac death within 30-days after acute myocardial infarction [13]. During the episode, i.e. the first month after acute myocardial infarction, the risk of sudden death is particularly high (Fig. 2) [14]. Early implantation of Implantable Cardioverter-Defibrillators was not found to be effective when performed within the first month after myocardial infarction [15], although later implantation of such devices have clearly shown their benefit. The beneficial effect of eplerenone in EPHESUS was observed despite the fact that treatment was initiated at a mean of 7.3 days after myocardial infarction, and an even earlier start, i.e. on day one, could potentially lead to even greater reduction in sudden cardiac death. Administration of ARAs was shown to be feasible within $24 \mathrm{~h}$ after myocardial infarction in a study on the effect of spironolactone on left ventricular remodelling [16]. Therefore, one may speculate that earlier use of eplerenone (in EPHESUS) could have led to an even larger beneficial effect.

In conclusion, when added to conventional therapy ARAs show benefits which are in addition to those conferred by ACE inhibitors and/or ARBs and beta-blockers. In eplerenone treated patients a substantial reduction of sudden cardiac death is observed early after myocardial infarction. The above mentioned non-genomic effects may possibly play a role in the observed effects. 


\section{References}

1. Swedberg K, Cleland JG, Dargie H et al (2005) Guidelines for the diagnosis and treatment of chronic heart failure: executive summary (update 2005): The Task Force for the Diagnosis and Treatment of Chronic Heart Failure of the European Society of Cardiology. Eur Heart J 26:11151140

2. Cohn JN, Tognoni G (2001) A randomized trial of the angiotensin-receptor blocker valsartan in chronic heart failure. N Engl J Med 345:16671675

3. Pfeffer MA, Swedberg K, Granger CB et al (2003) Effects of candesartan on mortality and morbidity in patients with chronic heart failure: the CHARM-Overall programme. Lancet 362(9386):759-766

4. Pitt B, Zannad F, Remme WJ et al (1999) The effect of spironolactone on morbidity and mortality in patients with severe heart failure. N Engl J Med 341:709-717

5. Pitt B, Remme W, Zannad F, Neaton J et al; of the Eplerenone Post-Acute Myocardial Infarction Heart Failure Efficacy and Survival study Investigators (2003) Eplerenone, a selective aldosterone blocker, in patients with left ventricular dysfunction after myocardial infarction. $\mathrm{N}$ Engl J Med 348:1309-1321
6. Van Veldhuisen DJ, Boomsma F, De Kam PJ et al (1998) Influence of age on neurohormonal activation and prognosis in patients with chronic heart failure. Eur Heart J 19:753-760

7. Teisman ACH, Van Veldhuisen DJ, Boomsma $\mathrm{F}$ et al (2000) Chronic beta-blocker treatment in patients with advanced heart failure. Effects on neurohormones. Int J Cardiol 73: $7-12$

8. Staessen J, Lijnen P, Fagard $\mathrm{R}$ et al (1981) Rise in plasma concentration of aldosterone during long-term angiotensin II suppression. J Endocrinol 91:457-465

9. McConnel JM, Davies E (2005) The new biology of aldosterone. J Endocrinol 186:1-20

10. Funder JW (2005) The nongenomic actions of aldosterone. Endocrin Rev 26:313-321

11. Mcdonald JE, Kennedy N, Struthers $\mathrm{AD}$ (2004) Effects of spironolactone on endothelial function, vascular angiotensin converting enzyme activity, and other prognostic markers in patients with mild heart failure already taking optimal treatment. Heart 90: 765-770
12. Pitt GS, Pitt B (2006) Aldosterone, ion channels and sudden death: another piece of the circle? Am J Physiol Heart Circ Physiol 290:H21762177

13. Pitt B, White H, Nicolau J et al (2005) Eplerenone reduces mortality 30 days after randomization following acute myocardial infarction in patients with left ventricular systolic dysfunction and heart failure. J Am Coll Cardiol 46:425-431

14. Solomon SD, Zelenkofske SD, McMurray JJ et al (2005) Sudden death in patients with myocardial infarction and left ventricular dysfunction, heart failure, or both. $\mathrm{N}$ Engl J Med 352:2581-2588

15. Hohnloser SH, Kuck KH, Dorian P et al (2004) DINAMIT Investigators. Prophylactic use of an implantable cardioverter-defibrillator after acute myocardial infarction. $\mathrm{N}$ Engl J Med 351:2481-2488

16. Hayashi M, Tsutamoto T, Wada A et al (2003) Immediate administration of mineralocorticoid receptor antagonist spironolactone prevents post-infarct left ventricular remodelling associated with suppression of a marker of myocardial collagen synthesis in patients with first anterior myocardial infarction. Circulation 107:2559-2565 